\title{
E-MRS Announces New Executive Officers, Fall Meeting, Summer School
}

\section{Stritzker is E-MRS President}

Following elections held during the 1991 E-MRS Spring meeting in Strasbourg, France, at the end of May, Bernd Stritzker, Institut für Festkörperforschung, Kernforschungsanlage, Jülich, Germany, has been named president of the European Materials Research Society.

For the first time, E-MRS also has two vice presidents. Piet F. Bongers from Philips Research Laboratories, Eindhoven, the Netherlands, is the new vice president, and Ian W. Boyd, University College London, United Kingdom, will occupy the position of second vice president.

The first president of E-MRS, Paul Siffert from Centre de Recherches Nucléaires, Strasbourg, was elected general secretary. G.G. Bentini, CNR Istituto Lamel, Bologna, Italy, who was president of E-MRS during 1989 and 1990, will be in charge of relations with other societies. Pierre Pinard from ENSI, Lyon, France, will continue as director of finance.

According to E-MRS statutes, elections are held every two years. Voting is accomplished through a previously elected Board of Delegates.

\section{E-MRS Fall Meeting Features Two-Part Program}

The 1991 E-MRS Fall Meeting, November $4-8,1991$ will feature seven symposia in a two-part technical program consisting of the 15th International Symposium on the Scientific Basis for Nuclear Waste Management and the E-MRS Conference Program.

Co-sponsored by MRS and the Commissariat à l'Energie Atomique (CEA), France, the 15th International Symposium on the Scientific Basis for Nuclear Waste Management includes four symposia:

Symposium A: 15th International Symposium on the Scientific Basis for Nuclear Waste Management. This symposium will focus on the science underlying the waste form (vitreous, bitumen, ceramic, spent fuel, cements); the near field environment (canister, backfill, radionuclide migration); and natural analogs.

Symposium B: Clays and Hydrosilicate Gels in Nuclear Fields. Topics will range from fundamental characterization of clays mineral and gels to applications. Emphasis will be on the kinetics of clay and gel reactions.

Symposium C: Solid State Chemistry of
Actinides. The focus will be on fundamental aspects of the chemistry of actinides as they relate to nuclear waste management, covering structure-bonding relationships in actinide waste solids, novel actinide waste forms, radiation and transmutation effects, characterization of solid actinide compounds by synchrotron radiation and other methods, and metrology of actinides.

Symposium D: Chemistry of Cements for Nuclear Applications. All aspects of experimental and theoretical advances in the chemistry of cements which can improve waste management and other nuclear applications will be addressed.

For more information about the 15th International Symposium on the Scientific Basis for Nuclear Waste Management, contact: Rod C. Ewing, University of New Mexico, Department of Geology, Albuquerque, NM 87131, phone (505) 277-4163, fax (505) 277-0090; or the organization committee: Arsène Saas, Department of Waste Management and Disposal, CEN Cadarache, F-13108 St. Paul lez Durance, France, phone (33) 42252720 , fax (33) 42254646 .

The E-MRS Fall Meeting Conference Program will feature three symposia:

Symposium E: Nuclear Materials for Fission Reactors. This symposium will bring together scientists interested in basic materials research, fabrication, application and technology as well as computer code modeling. Topics will span fuel fabrication and performance, reactor safety, basic properties of nuclear materials (fission and fusion reactors), and modeling of fuel performance.

Symposium F: Chemical and Physical Modifications Induced by Irradiation Glasses. The symposium will provide an overview of ion implantation into glasses, including defect creation, energy loss, radiation effects, and property changes for applications in optoelectronics, active glasses, and detectors.

Symposium G: Polyconjugated Materials - Chemistry, Physics, and Technology. Invited lectures will focus on polyconjugated organic materials exhibiting peculiar electrical and nonlinear optical properties. Novel chemical processes are being developed to synthesize better materials, and measuring and explaining the electrical and nonlinear optical properties are a challenge to experimental, theoretical, and computational physics.

For details about the 1991 E-MRS Fall
Meeting, contact: E-MRS/P.Siffert, C.T.T., B.P. 20, F67037 Strasbourg Cedex, France: phone (33) 882865 43; fax (33) 882809 90; telex 890032 CNRS CRO.

\section{Summer School to Cover Laser Ablation of Electronic Materials}

A roster of invited internationally recognized experts will introduce and review laser ablation etching or deposition of solids for microelectronics for attendees at the EMRS Summer School on Laser Ablation of Electronic Materials. The emphasis will be on basic understanding and applications.

The school will be held September 16 19, 1991 in Maubuisson, a small resort located $50 \mathrm{~km}$ west of Bordeau, France. It is being held under the sponsorship of the Council of Europe/European Parliament, the E-MRS Laser Processing and Superconductivity Network, IBM France, Direction des Recherches Etudes et Techniques, and the U.S. National Science Foundation.

The following topics will be covered:

- Introduction to ablation of dielectrics, metals, semiconductors, superconductors, refractory solids (diamond, BN, AIN);

- Basic mechanisms of ablation of polymers, metals, etc., plasma formation, emission of species, thermal/nonthermal processes;

- Diagnostics used in determining mechanisms-optical and mass spectroscopy, fast imaging, ionization, etc.; and

- Applications in new materials synthesis, surface patterning, instrumentation.

Participants (limited to 100) can present their work in a poster session. Papers presented during the school will be published by Elsevier/North Holland.

For more information contact one of the organizers: E. Fogarassy, CRN, Laboratoire PHASE, B.P. 20, 67037 Strasbourg Cedex, France, phone (33) 88286257 , fax (33) 882809 90; S. Lazare, Lab. de Photophysique et Photochimie Moléculaire, Université de Bordeaux, 351, Cours de la Libération, 33405 Talence Cedex, France, phone (33) 56846315 , fax (33) 56846645 , Bitnet LAZARE AT FRBDXII; J. Narayan, Dept. of Materials Science and Engineering, North Carolina State University, Raleigh, NC 27695-7916, USA, phone (1) (919) 7377874, fax (1) (919) 7377642. 